\title{
FORMAÇÃO INICIAL DE PROFESSORES E PROFESSORAS QUE ENSINAM MATEMÁTICA: interlocução dos conhecimentos escolar e do cotidiano
}

\author{
Rodrigo Tadeu Pereira da Costa \\ Cristiane Coppe de Oliveira
}

Resumo

Este texto é um recorte da tese de Costa (2021), defendida no Programa de Pós-Graduação em Educação da Universidade de São Paulo (USP). Trata-se de uma pesquisa que tem como objetivo analisar se é possível estabelecer uma ponte entre o conhecimento escolar e o conhecimento do cotidiano na formação inicial de professores e professoras que ensinam matemática. O solo teórico escolhido para a busca/refinamento dos dados coletados foram os estudos de Paulo Freire. Possui uma abordagem metodológica qualitativa, e os dados foram coletados através de entrevista semiestruturada. Os(as) entrevistados(as) são os líderes - coordenadores(as) ou vice-coordenadores(as) - dos oito grupos brasileiros cadastrados no diretório de grupos do CNPq, cujo nome inclui a palavra "Etnomatemática". O trabalho considera que o conhecimento do cotidiano também se caracteriza como um conhecimento científico, porém ele não é acadêmico e que o conhecimento do cotidiano pode, sim, dialogar com o conhecimento escolar. No entanto, esse diálogo vai depender de alguns fatores, como, por exemplo, o contexto e o interesse das partes em promover esse diálogo.

Palavras-chave: Paulo Freire; formação inicial de professores e professoras; matemática; pedagogia.

INITIAL EDUCATION OF TEACHERS WHO TEACH MATHEMATICS: interlocution between school knowledge and everyday knowledge

\section{Abstract}

This text is an excerpt from Costa (2021) thesis, defended in the Graduate Program in Education of the University of São Paulo (USP). It is a research that aims to analyze whether it is possible to establish a bridge between school knowledge and everyday knowledge in the initial education of teachers who teach Mathematics. The theoretical ground chosen for the search/refinement of the collected data were the studies by Paulo Freire. Has a qualitative methodological approach, and the data were collected through semi-structured interviews. The interviewees are the leaders - coordinators or vice-coordinators - of the eight Brazilian groups registered in the CNPq group directory, which includes the word "Ethnomathematics" in its name. The work considers that everyday knowledge is also characterized as scientific knowledge, but it is not academic and that everyday knowledge can indeed dialogue with school knowledge. However, this dialogue will depend on some factors, such as the context and the interest of the parties in promoting this dialogue.

Keywords: Paulo Freire; initial education of teachers; mathematics; pedagogy. 
DOI: $10.12957 /$ teias.2021.61733

\title{
FORMACIÓN INICIAL PARA PROFESORES QUE ENSEÑAN MATEMÁTICAS:
}

\author{
interlocución del conocimiento escolar y cotidiano
}

\section{Resumen}

Este texto es un recorte de la tesis de Costa (2021), defendida en el Programa de pos-graduación en Educación de la Universidad de São Paulo (USP). Esta investigación tiene como objetivo analizar si es posible establecer un puente entre el conocimiento escolar y el conocimiento cotidiano en la formación inicial de los docentes que enseñan matemáticas. El fundamento teórico elegido para la búsqueda/refinamiento de los datos recolectados fueron los estudios de Paulo Freire. Tiene un enfoque metodológico cualitativo, y los datos fueron recolectados mediante de entrevistas semiestructuradas. Los entrevistados son los líderes - coordinadores o vice-coordinadores - de los ocho grupos brasileños registrados en el directorio de grupos del CNPq, cuyo nombre incluye la palabra "Etnomatemáticas". El trabajo considera que el conocimiento cotidiano también se caracteriza como conocimiento científico, pero no es académico y que el conocimiento cotidiano sí puede dialogar con el conocimiento escolar. Sin embargo, este diálogo dependerá de algunos factores, como el contexto y el interés de las partes en promover este diálogo.

Palabras clave: Paulo Freire; formación inicial para profesores; matemáticas; pedagogía.

\section{INTRODUÇÃO}

$\mathrm{Na}$ literatura disponível sobre o tema formação de professores(as), podemos constatar que são muitos os autores que o discutem. Concordamos com Domite $(2000$, p. 4) ao dizer que "[...] o aluno e a aluna não têm estado de todo fora das propostas de formação de professores, mas também não estão dentro". Diante disso, a principal motivação para este trabalho pautou-se na afirmação de Domite (2011) de que algumas propostas de formação de professores(as) têm sido valiosas se forem levadas em consideração tais discussões na perspectiva do Programa Etnomatemática, em especial as que se inspiram nas ideias de Paulo Freire.

Segundo D’Ambrosio (2005, p. 102), a Etnomatemática “[...] é um estudo da evolução cultural da humanidade no seu sentido amplo, a partir da dinâmica cultural que se nota nas manifestações matemáticas". O termo designa um programa que reconhece que todas as culturas produzem conhecimento matemático. A Etnomatemática procura entender o saber e o fazer da matemática ao longo da história da humanidade, em diferentes contextos culturais. Aproximamonos de Paulo Freire à medida que, assim como no Programa Etnomatemática, o autor situa o processo de ensino e aprendizagem na cultura do educando e da educanda.

Diante dos pressupostos, este estudo tem como questão norteadora: é possível estabelecer uma ponte entre o conhecimento escolar e o conhecimento do cotidiano na formação inicial de professores e professoras que ensinam matemática? $\mathrm{E}$, para responder tal questionamento, traçamos como objetivo analisar se é possível estabelecer uma ponte entre o conhecimento escolar e o conhecimento do cotidiano na formação inicial de professores e professoras que ensinam matemática.

Nesse sentido, este trabalho apresentará as percepções dos dados levantados, buscando oferecer contribuições de relevância para a discussão da presença do conhecimento do cotidiano dos educandos e das educandas na formação inicial de professores(as) que ensinam matemática, envolvendo, portanto, os cursos de graduação em matemática e em pedagogia. 
DOI: $10.12957 /$ teias.2021.61733

\section{A FORMAÇÃO DE PROFESSORES E PROFESSORAS NA PERSPECTIVA FREIRIANA}

Paulo Freire aborda a formação de professores(as) em seus diversos trabalhos, provenientes de suas experiências como educador e das discussões que teve com outros(as) docentes em vários países por onde passou. Identificamos que sua preocupação não se resume a estabelecer um modelo de formação inicial dos(as) professores(as), pois seus estudos se voltam à formação de professores e professoras como um percurso durante toda a vida no magistério e levaram Freire (1992, p. 11) a ponderar:

Não era esta a minha posição ontem e não é esta a minha posição hoje. E hoje,
tanto quanto ontem, contudo possivelmente mais fundamentado hoje do que
ontem, estou convencido da importância, da urgência da democratização da
escola pública, da formação permanente de seus educadores e educadoras entre
quem incluo vigias, merendeiras, zeladores. Formação permanente, científica, a
que não falte sobretudo o gosto das práticas democráticas, entre as quais a de
que resulte a ingerência crescente dos educandos e de suas famílias nos destinos
da escola.

Ao defender uma formação permanente de professores(as), Paulo Freire não está se distanciando da formação inicial; pelo contrário, está propondo que eles estejam em constante processo de formação, ficando evidente que suas contribuições abrangem também a formação inicial. As teorias pedagógicas de Freire são voltadas às classes oprimidas, que buscam sua libertação, e o educador e a educadora precisam estar a serviço dessa libertação. No entanto, "[...] ninguém liberta ninguém, ninguém se liberta sozinho" (FREIRE, 1987, p. 29) - devem se libertar em comunhão, mediante o diálogo. Cabe ao professor e à professora instaurarem o diálogo, pois a relação dialógica implica uma prática problematizadora do(a) professor(a) e do(a) educando(a), que se relacionam no processo de ensino e aprendizagem.

Nesse processo, o(a) professor(a) ensina o que sabe e aprende novas experiências com $o$ (a) educando(a), assim como o(a) educando(a) aprende o que não sabe e, ao mesmo tempo, ensina suas experiências ao(à) professor(a). É uma troca de vivências, pois a educação, nessa perspectiva, não se faz de "A" para "B" ou de "A" sobre "B", mas de "A" com "B" (FREIRE, 1967). Nesse sentido, defendemos que o(a) professor(a) se adapte à realidade do(a) educando(a), levando em consideração o saber que ele traz do seu contexto para a construção do seu conhecimento. Assim, faz sentido o que o(a) aluno(a) está aprendendo.

Com o diálogo, um cresce com o outro, em uma troca contínua de experiências. Todavia, o diálogo só ocorre se houver amor, humildade, fé nos homens, esperança e pensar crítico (FREIRE, 1967). Isso porque, diante de uma relação de dominação, sem a presença de amor, não há diálogo, assim como tampouco há diálogo com uma pessoa que se considera dona da verdade e faz do seu conhecimento o único verdadeiro. Desse modo, também não há diálogo se não existe confiança no pensar verdadeiro.

Sem diálogo, ocorre uma educação mecânica, na qual o(a) professor(a) apenas deposita ou transfere os conteúdos, que os(as) educandos(as) memorizam e repetem. Essa visão bancária, com depósitos e transferências de conteúdos, limita a criação dos(as) alunos(as), assim como sua criticidade, satisfazendo apenas o interesse dos(as) opressores(as).

A concepção bancária da educação que, assim como Freire (1987), criticamos advém de uma repetição do conteúdo, que só vai abarrotando os educandos e as educandas com conhecimentos impostos, resultando em um saber falso. Portanto, neste trabalho defendemos, 
como Freire (1987, p. 47), uma prática problematizadora do(a) professor(a), em que o(a) educando(a) desenvolve a capacidade de compreender o mundo. A visão bancária da educação e a visão problematizadora se afastam, pois:

[...] a "bancária", por óbvios motivos, insiste em manter ocultas certas razões que explicam a maneira como estão sendo os homens no mundo e, para isto, mistifica a realidade. A problematizadora, comprometida com a libertação, se empenha na desmitificação. Por isto, a primeira nega o diálogo, enquanto a segunda tem nele a indispensável relação ao ato cognoscente, desvelador da realidade. A primeira "assistencializa"; a segunda, criticiza. A primeira, na medida em que, servindo à dominação, inibe a criatividade e, ainda que não podendo matar a intencionalidade da consciência como um desprender-se ao mundo, a "domestica", nega os homens na sua vocação ontológica e histórica de humanizar-se. A segunda, na medida em que, servindo à libertação, se funda na criatividade e estimula a reflexão e a ação verdadeiras dos homens sobre a realidade, responde à sua vocação, como seres que não podem autenticar-se fora da busca e da transformação criadora.

Diante disso, cabe ao professor e à professora promover o diálogo, na busca de um pensar crítico de seus educandos e suas educandas e da libertação dos oprimidos. Assim sendo, Freire (1996) defende um(a) professor(a) libertador(a). Ora, o(a) professor(a) libertador(a) “[...] não pode negar-se o dever de, na sua prática docente, reforçar a capacidade crítica do educando, sua curiosidade, sua insubmissão" (FREIRE, 1996, p. 13). Para isso, ele(ela) precisa criar possibilidades para a produção e a construção do conhecimento.

$\mathrm{O}$ (a) professor(a) não pode transferir conhecimento, e sim criar condições para que os(as) educandos(as) construam e reconstruam o saber. Além disso, o educador e a educadora precisam estar abertos às curiosidades e às perguntas dos(as) alunos(as).

Estimular os(as) educandos(as) a perguntarem é primordial em um curso de formação inicial de professores(as). Nesse sentido, o(a) professor(a) formador(a) necessita ser ético e respeitar a curiosidade do(a) educando(a), uma vez que não existem perguntas tolas; ser "tolo" é não estimular $\mathrm{o}(\mathrm{a})$ futuro(a) professor(a) a perguntar e privá-lo de um conhecimento que vai ser útil a ele(ela) em algum momento de sua vida. Vivemos em uma sociedade heterogênea e os(as) educandos(as) apresentam várias visões do mundo, que estão relacionadas com o seu contexto social, cultural, histórico e o seu imaginário; portanto, são detentores de curiosidades e indagações diferentes. $\mathrm{O}(\mathrm{a})$ professor(a) formador (a) libertador(a) não domestica $\mathrm{o}(\mathrm{a})$ futuro(a) professor(a), tampouco ensina somente o conteúdo: ele apoia o(a) educando(a) a “[...] reconhecer-se como arquiteto de sua própria prática cognoscitiva" (FREIRE, 1996, p. 47).

Além disso, como Freire (1996), defendemos um(a) professor(a) livre de qualquer tipo de preconceito, seja de raça, classe, gênero, orientação sexual, cultural, entre outros; um(a) professor(a) que respeite as diferenças em todas suas variadas dimensões; um(a) professor(a) que seja democrático, lute pela libertação dos oprimidos e enalteça os conhecimentos marginalizados, assim como os conhecimentos a priori dos(as) educandos(as).

Em entrevista para o International Congress on Mathematical Education (ICME 8), realizado em 1996 em Sevilla, na Espanha, Paulo Freire dialoga com os educadores matemáticos Ubiratan D’Ambrosio e Maria do Carmo Domite sobre a Educação Matemática e a formação de professores(as).

Ao ser questionado sobre o domínio da matemática para que o ser humano possa ser livre, Paulo Freire afirma não ter dúvida de que a alfabetização matemática ajudaria enormemente 
a criação da cidadania. Isso porque, no momento em que se traduz a naturalidade da matemática como condição de estar no mundo, se trabalha contra um certo elitismo, democratizando a possibilidade de naturalizar a matemática.

Paulo Freire ainda comenta sobre o desprestígio do senso comum ao apontar a postura elitista da escola em deixar de lado a contribuição do(a) educando(a), supervalorizando o conhecimento dito acadêmico diante da desvalorização do conhecimento do senso comum. Para ele, o ponto de partida da prática educativa não deve ser a compreensão do mundo que tem o(a) professor(a), mas sim a compreensão do mundo do(a) educando(a), partindo do que esses sabem, para que possam saber mais e melhor.

Essas considerações sobre o ideário de Paulo Freire revelam uma conexão entre suas teorizações e o Programa Etnomatemática. De acordo com D’Ambrosio (2004, p. 45):

[...] o Programa Etnomatemática não se esgota no entender o conhecimento [saber e fazer] matemático das culturas periféricas. Procura entender o ciclo da geração, organização intelectual, organização social e difusão desse conhecimento. Naturalmente, no encontro de culturas há uma importante dinâmica de adaptação e reformulação acompanhando todo esse ciclo, inclusive a dinâmica cultural de encontros [de indivíduos e de grupos].

Um dos objetivos do Programa Etnomatemática é fortalecer as raízes culturais de grupos marginalizados, além de mostrar outras formas de construir o conhecimento. Diante disso, constatamos que as propostas pedagógicas de Freire, sejam elas para o ensino de uma maneira geral, sejam para formação de professores(as), se entrelaçam com a Etnomatemática, uma vez que ambas se preocupam com o conhecimento que o(a) educando(a) da Educação Básica ou o(a) professor(a) em formação trazem do ambiente informal para o ambiente formal de aprendizagem.

\section{DELINEANDO UM CAMINHO PARA A PESQUISA}

A investigação tem natureza qualitativa. De acordo com Alves-Mazzotti e Genvandsznajder (1999, p. 131):

[...] a principal característica das pesquisas qualitativas é o fato de que estas seguem a tradição "compreensiva" ou interpretativa. Isto significa que essas pesquisas partem do pressuposto de que as pessoas agem em função de suas crenças, percepções, sentimentos e valores e que seu comportamento tem sempre um sentido, um significado que não se dá a conhecer de modo imediato, precisando ser desvelado.

Para este trabalho, fez-se uso da entrevista semiestruturada por acreditar que ela forneceria uma melhor resposta ao problema de pesquisa. Defendemos esse método porque, por meio dela, se cria uma interação de diálogo entre o(a) pesquisador(a) e o(a) entrevistado(a). Buscamos, nesse nosso diálogo, assim como pontua Freire (1967), uma troca de experiência, para que entrevistador e depoente aprendam um com o outro. Cabe ressaltar que, durante as entrevistas, assumimos uma postura de escuta acerca dos depoimentos, pois "[...] somente quem escuta paciente e criticamente o outro, fala com ele", uma vez que saber escutar é indispensável no processo dialógico (FREIRE, 1996, p. 43). 
Domite (2011, p. 5) relata que, para iniciar um diálogo em relação à Etnomatemática, costumava propor perguntas para professores(as) e educadores(as) e professores(as) em formação. Para este trabalho, focamos nas perguntas a seguir:

1. A "matemática" é uma produção social, gerada de motivações práticas; ou e e/ou A "matemática" é uma estrutura abstrata com símbolos bem definidos uma linguagem - de cunho axiomático-dedutivo, construída a partir de um jogo intelectual. É também uma produção social? 2. O conhecimento (matemático) primeiro é tão legítimo a ponto de poder dialogar com o conhecimento (matemático) dito científico? É ou não? Para quem? 3. É possível/valioso do ponto de vista afetivo-cognitivo fazer o trânsito/ponte entre os conhecimentos étnicos (ou conhecimento primeiro) e os conhecimentos ditos científicos? É possível construir esta ponte? 4. O conhecimento (matemático) construído no fazer-saber de um grupo social é, em geral, validado pela experiência. Tem este conhecimento valor de troca no mercado? 5 . Há outros modos de compreender e explicar as relações quantitativas e espaciais que não somente pela "matemática" que conhecemos. Há outras "matemáticas"?

Percebemos a importância de tais perguntas para iniciar um diálogo na formação de professores(as) na perspectiva da Etnomatemática e, por isso, para a entrevista realizada neste trabalho, utilizamos as perguntas aqui transcritas.

Para delimitar os sujeitos desta pesquisa, buscamos no diretório do $\mathrm{CNPq}$ os grupos em Etnomatemática. Nesse sistema, podemos pesquisar um grupo utilizando palavras-chave e, quando pesquisada a palavra Etnomatemática, colocamos como opção "nome do grupo" e chegamos a um montante de oito grupos ${ }^{1}$. Tais grupos são objetos de estudo deste trabalho e são apresentados na Tabela 1 a seguir, com seu ano de criação, o nome do grupo, Instituição de Ensino Superior (IES) a qual estão vinculados e seu(sua) líder.

Tabela 1: Grupos de estudos com a palavra Etnomatemática no nome

\begin{tabular}{|c|c|c|c|}
\hline Ano & Grupo & IES & Líder(es) \\
\hline 1999 & $\begin{array}{l}\text { Grupo de Estudos e Pesquisas em } \\
\text { Etnomatemática (GEPEm) }\end{array}$ & Universidade de São Paulo & $\begin{array}{l}\text { Vinicio de Macedo Santos e } \\
\text { Ubiratan D'Ambrosio }\end{array}$ \\
\hline 2004 & $\begin{array}{l}\text { Grupo de Estudo e Pesquisa em } \\
\text { Etnomatemática (GEPEtno) }\end{array}$ & $\begin{array}{l}\text { Universidade Estadual } \\
\text { Paulista }\end{array}$ & $\begin{array}{l}\text { Ubiratan D'Ambrosio e Roger } \\
\text { Miarka }\end{array}$ \\
\hline 2008 & $\begin{array}{l}\text { Grupo de Estudos e Pesquisas em } \\
\text { Etnomatemáticas Negras e Indígenas } \\
\text { (GEPENI) }\end{array}$ & $\begin{array}{l}\text { Universidade Federal do Mato } \\
\text { Grosso }\end{array}$ & $\begin{array}{l}\text { Wanderleya Nara Gonçalves Costa e } \\
\text { Admur Severino Pamplona }\end{array}$ \\
\hline 2012 & $\begin{array}{l}\text { Grupo de Estudos e Pesquisa em } \\
\text { Etnomatemática (GEPEPUCRS) }\end{array}$ & $\begin{array}{l}\text { Pontifícia Universidade } \\
\text { Católica do Rio Grande do } \\
\text { Sul }\end{array}$ & Isabel Cristina Machado de Lara \\
\hline 2012 & $\begin{array}{l}\text { Grupo de Estudos e Pesquisas das } \\
\text { Práticas Etnomatemáticas na } \\
\text { Amazônia (GETNOMA) }\end{array}$ & Universidade Federal do Pará & $\begin{array}{l}\text { Osvaldo dos Santos Barros e Odirley } \\
\text { Ferreira da Silva }\end{array}$ \\
\hline 2013 & $\begin{array}{l}\text { Grupo de Etnomatemática da } \\
\text { Universidade Federal Fluminense } \\
\text { (GETUFF) }\end{array}$ & $\begin{array}{l}\text { Universidade Federal } \\
\text { Fluminense }\end{array}$ & $\begin{array}{l}\text { Maria Cecilia de Castello Branco } \\
\text { Fantinato e Adriano Vargas Freitas }\end{array}$ \\
\hline 2016 & Etnomatemática na Universidade & Universidade Federal de Ouro & Daniel Orey e Milton Rosa \\
\hline
\end{tabular}

${ }^{1}$ Busca feita no ano de 2018. 
DOI: $10.12957 /$ teias.2021.61733

\begin{tabular}{|l|l|l|l|}
\hline & Federal de Ouro Preto (EUFOP) & Preto & \\
\hline 2018 & Grupo Interdisciplinar de Estudo e & Universidade da Integração & Eliane Costa Santos \\
& Pesquisa em Etnomatemática & Internacional da Lusofonia & \\
& (GIEPEM) & Afro-Brasileira & \\
\hline
\end{tabular}

Fonte: Organizado pelos autores a partir do Diretório de grupos de pesquisa do CNPq.

Os(as) professores(as) destacados(as) no Quadro 1 foram aqueles que nos concederam entrevistas. Para organizar e analisar os dados obtidos por meio das entrevistas, optamos por um processo de categorização. Para este estudo, apresentamos as discussões referente à categoria interlocução dos conbecimentos escolares e do cotidiano.

\title{
INTERLOCUÇÃO DOS CONHECIMENTOS ESCOLAR E DO COTIDIANO
}

\author{
Há inúmeras situações-problema e soluções do contexto não \\ escolar - que resultam do trânsito por diferentes áreas do \\ conhecimento e são validados/compartilhados pela experiência \\ - que a matemática que aprendemos no contexto escolar não \\ nos deixa perceber, talvez. pelo fato da tradição de \\ valorizarmos sempre um tipo de matemática - a matemática \\ construida na academia, em geral, livre de contextos. [...] \\ quando percebemos tais situações-problema como situações \\ ricas em termos de matemática - possivelmente geradoras de \\ uma aula de matemática - a construção de uma ponte entre \\ este tal conjunto de ideias (matemáticas) e aquele \\ sistematizado pela escola é colocada em risco devido às inter- \\ relações entre o pensamento e a emoção, o pensamento e as \\ tradições, o pensamento e a religião, o pensamento e os mitos \\ que levam a situações inesperadas em virtude da tendência da \\ linguagem para assumir diferentes significados. Na verdade, \\ para que esta ponte ocorra é, muitas vezes, necessária uma \\ tradução entre discursos por meio de uma atenção cuidadosa \\ aos significados, às representações e, muitas vezes, a elementos \\ linguísticos. (DOMITE, 2011, p. 10)
}

Por diversos momentos nos deparamos com situações em que os(as) educandos(as) questionam seus(suas) professores(as) com perguntas do tipo: "Para que serve essa matemática?" ou "Onde vou usar essa matemática na minha vida?". Essas indagações são feitas porque, muitas vezes, a matemática que se aprende na escola não deixa os(as) educandos(as) perceberem o quão útil ela é na nossa vida.

Conforme o(a) aluno(a) vai progredindo no sistema escolar e aumentando a complexidade do conteúdo a ser estudado, mais dificuldades os(as) professores(as) encontram em relacionar os conteúdos estabelecidos pelo currículo com aqueles vivenciados no cotidiano dos(as) estudantes. Sem dúvida, a interlocução entre os conhecimentos escolares e os do cotidiano é um desafio na formação inicial de professores(as) que ensinam matemática.

Buscamos convergências na fala dos(as) depoentes para analisar se é possivel estabelecer uma conexão entre esses conhecimentos na formação inicial de professores(as) que ensinam matemática. Para o professor Ubiratan D’Ambrosio: 
O conhecimento matemático primeiro vem de satisfação das necessidades. Bom, chega um momento onde você tem a socialização, aquilo que o indivíduo fez e pensou como indivíduo é socializado com outros indivíduos e grupos, socializado de que modo? Principalmente através de comunicação, e comunicação quer dizer gestos, palavras e um monte de coisa, ele é comunicado entre todos e nessa comunicação surge a necessidade de alguma forma de sintetizar essa comunicação numa forma de linguagem. Essa linguagem formaliza aquilo que o sujeito tá pensando, formaliza o abstrato num certo sentido. $\mathrm{O}$ abstrato, o que você pensa fica só para você, não é transmitido para o outro, mas, uma vez transformado em algo concreto que o outro pode perceber, por exemplo, a linguagem, a escrita, o desenho, tudo isso pode ser captado pelo outro, não pelo que pensou inicialmente, o primeiro, mas por outros. Nesse momento, você começa a criar mecanismos melhores de comunicação. Esses mecanismos melhores de comunicação acabam se organizando na forma de conhecimento científico, religioso, vários tipos de conhecimento, um deles, que é conhecimento ligado às estratégias de sobrevivência de natureza matemática acaba, assim, dando origem àquilo que a gente chama de matemática formal. Não há separação das duas. (D'AMBROSIO, 2018, entrevista)

Para o depoente, não há separação entre o conhecimento matemático primeiro, que vem da satisfação das necessidades de sobrevivência, e o conhecimento científico, pois, quando o sujeito socializa através da comunicação o que fez e pensou, os mecanismos da comunicação (linguagem, escrita, desenho, entre outros) acabam se organizando na forma de conhecimento científico.

Nesse mesmo sentido, a professora Eliane Costa Santos ressalta que "[...] saber-fazer é o mesmo conhecimento científico que se tem. Um povo não pode ter conhecimento e outro povo apenas o saber-fazer" (SANTOS, 2019, entrevista), e ainda "[...] esse saber-fazer, para mim, é um conhecimento científico. Então eu não consigo pensar nesse saber-fazer, se não for pensar na cientificidade existente no fazer no conhecimento, eu não consigo distinguir isso" (SANTOS, 2019, entrevista). Ou seja, ela acredita que o saber fazer também se caracteriza como conhecimento científico.

Já a professora Maria Cecilia de Castello Branco Fantinato relata: "Eu vejo isso como um emaranhado. Assim, por exemplo: dentro dessas experiências primeiras também entra, às vezes, o conhecimento matemático dito científico, dependendo se elas estão em um ambiente mais letrado" (FANTINATO, 2019, entrevista). Ou seja, ela considera que, algumas vezes, o conhecimento matemático primeiro e o científico estão imbricados.

Nesse mesmo sentido, o professor Milton Rosa reflete se o conhecimento primeiro ou o local também não seria um conhecimento científico e expõe: "Por exemplo, o conhecimento primeiro: eles podem adotar práticas matemáticas do conhecimento científico - dito científico - e também vice-versa, o conhecimento científico também pode adotar algumas práticas matemáticas que são locais, né?” (ROSA, 2018, entrevista).

O depoente indica que o conhecimento matemático local pode adotar algumas práticas matemáticas científicas e o conhecimento científico também pode adotar algumas práticas matemáticas locais. E ressalta, em outro momento, que o conhecimento local também é científico, mas não acadêmico.

Já o professor Osvaldo dos Santos Barros considera que a dualidade entre o saber empírico e o conhecimento científico não funciona. Para ele: 
[...] o saber, ele não é simplesmente aquilo que não é científico. Não: é aquilo que é dominado. Porque, se a gente estabelece só o que o saber é aquilo empírico e o conhecimento é aquilo que é provado cientificamente, a gente estabelece uma dualidade que não funciona direito, né? Isso aí só fica em prol da própria ciência e não dos outros tipos de conhecimentos, as outras fontes de conhecimento, né? (BARROS, 2019, entrevista)

Apesar de ser denominado de maneira diferente por nós ou pelos(as) depoentes, como, por exemplo, conhecimento primeiro ou conhecimento local, entendemos esse conhecimento como o conhecimento do cotidiano, seja do cotidiano do(a) educando(a) ou de um grupo cultural diverso.

Para não se constituir como um obstáculo no processo de ensino-aprendizagem, na formação inicial o(a) professor(a) formador(a) é preciso respeitar o conhecimento que o educando e a educanda trazem de suas experiências primeiras, com raízes em sua cultura. Assim sugere Freire (1967) em sua proposta de levar em consideração o conhecimento prévio do(a) educando(a) e a cultura de cada um(uma) no seu processo de formação. Esse conhecimento do cotidiano, como podemos perceber na fala convergente dos(as) depoentes, também se caracteriza como um conhecimento científico, embora não escolar.

O Programa Etnomatemática tem como objetivo entender o ciclo do conhecimento em diversos tipos de ambientes, entre eles, o ambiente escolar e as práticas cotidianas da sociedade. Para D'Ambrosio (2018, p. 12), precisamos de uma nova concepção de rigor, em que a integração da matemática com os "[...] conhecimentos tradicionais possa ser materializada de forma espontânea, sem traumas de natureza epistemológica. Isso exige coragem e audácia". Isso implica uma nova postura do(a) professor(a) formador(a) de professores(as), ao fazer a interlocução do conhecimento do cotidiano com o conhecimento escolar na formação inicial, fazendo, se necessário, uma educação fundamentada no diálogo.

Para a professora Eliane Costa Santos, o saber escolar pode dialogar com os saberes indígenas e africanos, desde que haja respeito e se compreenda que não há apenas o saber eurocêntrico, como podemos perceber na fala da depoente:

Porque é só você compreender e respeitar a cultura do outro, você consegue perceber o que pode ser olhado em um e ser legitimado no outro. É isso que faz a gente poder tratar de uma outra cultura dentro da nossa, é isso que a gente pode, faz a gente pensar, que a cultura escolar pode dialogar muito bem com a cultura que está - a cultura primeira, como você traz, né? Com os saberes de outros povos: dos povos indígenas, dos povos africanos... É que só consegue trazer essa cultura escolar, fazer essa cultura escolar dialogar, se a gente conseguir perceber o respeito que a gente precisa ter de ouvir o que o outro traz e não achar que existe uma única forma de cultura - que é a cultura eurocêntrica. (SANTOS, 2019, entrevista)

Nesse mesmo sentido, o professor Milton Rosa considera possível o diálogo entre o conhecimento primeiro e o científico e ressalta:

E isso pra mim entraria numa questão, que você fala, do diálogo, entraria pra mim numa questão freiriana, que seria a questão dialógica, né?, em que os dois conhecimentos estão dialogando, né? E cada um deles se beneficiando dessas práticas. Claro que aí nós, os elementos desses grupos, eles teriam que estar atentos para que uma imposição de conhecimentos não ocorra, aí teria que ser o diálogo mesmo. E esse diálogo nós comentamos que teria que ser uma 
tradição - uma tradição não: uma tradução entre os conhecimentos ou entre sistemas de conhecimentos que são diferenciados. E essa tradução, do meu ponto de vista, ela pode acontecer dialogicamente. Então, nós entendemos... Para quem esse conhecimento - eu acho para os dois lados, né? (ROSA, 2018, entrevista)

O depoente indica a ação dialógica proposta por Paulo Freire para o diálogo entre o conhecimento primeiro e o científico. Além disso, reforça que a interação dialógica entre conhecimentos distintos tende a beneficiar os dois lados.

Já a professora Fantinato, ao ser questionada se o conhecimento matemático primeiro pode dialogar com o conhecimento matemático científico, afirma: "Ele dialoga, sim, mas não sempre [...] as pessoas têm muitos conhecimentos, têm meios, e depende das experiências delas, das experiências de trabalho, experiências de vida, da... do grupo social a que elas pertencem" (FANTINATO, 2019, entrevista). Ou seja, a docente considera que nem sempre o conhecimento primeiro dialoga com o conhecimento científico, pois há uma interferência das experiências do sujeito.

O professor Osvaldo dos Santos Barros reforça essas afirmações e complementa que "[...] nós temos que ver essa situação de legitimidade e a quem ele é legítimo para a gente poder dizer se ele dialoga ou não. E muitas vezes ele dialoga, mas não no sentido de valorização do que ele é, mas de adaptação àquilo que a ciência quer que ele faça" (BARROS, 2019, entrevista). O depoente considera que, para o conhecimento científico dialogar com o conhecimento primeiro, precisa-se ver para quem esse conhecimento é legítimo.

Wanderleya Nara Gonçalves Costa reforça que essa legitimidade vai depender do contexto, pois:

[...] para discutir sobre o poder do diálogo que esse conhecimento matemático legitimado nesse contexto primeiro possa ter com o conhecimento matemático científico, eu acho importante pensar em qual contexto esse diálogo acontecerá. Por exemplo: digamos que um acadêmico - não necessariamente um etnomatemático - vá até uma aldeia indígena. Então ele está lá no contexto em que o conhecimento primeiro foi gerado. Se a busca for pelo diálogo, e não pela imposição, o detentor do conhecimento científico não pode fazer uso apenas de argumentos baseados na estrutura axiomática da matemática; ele deve demonstrar na ação, na implementação do projeto coletivo daquele povo indígena, que o conhecimento matemático acadêmico é válido também para aquele contexto. Entretanto, para o diálogo acontecer dentro da própria academia ou no ambiente escolar, eu penso que seja necessário que os detentores do conhecimento científico reconheçam a existência, a validade e a importância de outros conhecimentos matemáticos - ou etnomatemáticos. (COSTA, 2019, entrevista)

A depoente propõe pensar em qual contexto acontecerá o diálogo do conhecimento matemático primeiro com o científico e aponta que, para isso ocorrer, é necessário que os detentores do conhecimento científico reconheçam a importância dos outros conhecimentos etnomatemáticos.

Nesse mesmo sentido, a professora Isabel Cristina Machado de Lara relata:

Sim, obviamente eles podem dialogar, mas não significa que necessariamente em qualquer contexto eles podem ser legitimados. O que pode ser legítimo dentro da academia pode não resolver uma situação-problema de um agricultor, 
do mesmo modo que a forma de matematizar dentro de uma construção civil feita por um pedreiro nem sempre vai ser válida para resolver uma situação matemática mais complexa, mais teórica, então para quem?, tudo isso depende do contexto, tudo isso depende da prática social onde esse saber está sendo gerado organizado e difundido. (LARA, 2020, entrevista)

A depoente acredita que os diferentes modos de matematizar, muitas vezes, não são suficientes em outros contextos. Ou seja, a matemática escolar nem sempre é o bastante para resolver todos os problemas dos diferentes grupos culturais, do mesmo modo que os saberes etnomatemáticos, muitas vezes, não se fazem no ambiente escolar. Afirma, ainda, que a sua legitimidade está associada à sua validade.

Os apontamentos dos(as) depoentes deixam claro que o conhecimento do cotidiano pode, sim, dialogar com o conhecimento escolar. No entanto, esse diálogo vai depender de alguns fatores, como, por exemplo, o contexto e o interesse das partes em promover esse diálogo.

No contexto da formação inicial de professores(as), o(a) docente formador(a) é o mediador(a) que precisa promover essa interlocução do conhecimento do cotidiano com o escolar através do diálogo, pois, em uma educação antidialógica, o(a) professor(a) deposita no educando e na educanda conteúdos que, muitas vezes, não fazem sentido a eles(elas). Porém, na prática dialógica, esse conteúdo se organiza e se constitui a partir da visão de mundo dos(as) educandos(as), pois o conteúdo não é mais imposto pelo professor, e sim nasce do diálogo entre professores(as) e educandos(as), que reflete seus anseios e esperanças (FREIRE, 1987).

Cabe ao(à) professor(a) formador(a) considerar em sua prática o conhecimento prévio do(a) futuro(a) professor(a) e, através do diálogo, construir uma ponte entre o conhecimento do cotidiano do educando e da educanda e o conhecimento escolar, pois:

[...] você tem que partir do princípio que você tem a aprender com o outro. Isso... Se você não tem esse princípio não vai funcionar esse diálogo, não vai funcionar essa ponte. E eu vou dizer mais: e tem que ser de um lado e de outro, né? Eu acho que tem que ser em via de mão dupla também, né? Do conhecimento cotidiano para o conhecimento mais acadêmico e via de mão dupla também acho que há uma, um mútuo. (FANTINATO, 2019, entrevista)

A professora Maria Cecilia de Castello Branco Fantinato indica a importância de refletir que você aprende com o outro, pois somente assim o diálogo e, consequentemente, a ponte entre o conhecimento primeiro e o científico vai funcionar. Para Freire (1987, p.12), "[...] quem ensina aprende ao ensinar e quem aprende ensina ao aprender".

A professora Wanderleya Nara Gonçalves Costa afirma a esse respeito:

Tal como qualquer ponte, essa que se queira construir entre os diferentes conhecimentos será edificada em determinado lugar, sob determinadas circunstâncias; logo, o modelo de ponte pelo qual se possa transitar entre os conhecimentos etnomatemáticos de um grupo e o conhecimento científico não poderá simplesmente ser transposto para um outro contexto, para estabelecer a relação entre conhecimento científico e outra Etnomatemática. Há que se efetuar todo um trabalho de pesquisa, de reconhecimento, de valorização de saberes locais, que permita a construção de uma outra ponte. Mas eu acho que vale a pena, é isso que nos move enquanto pesquisadores em etnomatemática. (COSTA, 2019, entrevista) 
A depoente considera que se deve pensar como será feita a ponte entre os conhecimentos primeiros e os científicos, sem transpô-los apenas, mas sim valorizando os saberes locais. Para Freire (1987, p. 12), "[...] ensinar não é transferir conhecimento, mas criar as possibilidades para a sua produção ou a sua construção".

Nesse mesmo sentido o professor Ubiratan D’Ambrosio aponta a necessidade de uma linguagem adequada nessa transição, ao fazer a ponte entre os conhecimentos étnicos e os científicos. Já o professor Milton Rosa, ao se perguntar se é possível fazer a ponte entre o conhecimento primeiro e o científico, relata que:

[...] muitos vão dizer que não, né?, que essa construção dessa ponte não é possível e que é muito difícil de ser realizado. Eu prefiro dizer que existe uma dificuldade na construção dessa ponte, né?, entre esses dois conhecimentos (o conhecimento primeiro - local - com o conhecimento dito científico ou o conhecimento global...), mas, apesar dessa dificuldade, eu acredito que essa possibilidade exista, dessa ponte [...]. Agora, nós temos que tomar alguns cuidados, né? Alguns cuidados para que essa ponte né?, como você chama, também tem a questão da afetividade aí - e porque da afetividade e da cognição, porque quando você usa elementos da própria cultura o aluno se sente representado naquilo que você tá propondo, aí tem a questão da afetividade porque ele se reconhece na escola nessa questão. E na cognição também, né?, porque ele aprende lá fora de uma maneira diferente da que ele tá aprendendo na sala de aula, então isso. E essa ponte também, eu acho, entre a afetividade e o aspecto cognitivo também é importante de ser feito, né? Tomando certos cuidados, claro. (ROSA, 2018, entrevista)

O professor Rosa acredita que exista uma dificuldade, embora seja possível fazer a ponte entre o conhecimento local e o conhecimento global. Ele indica que se tome cuidado ao fazer essa conexão, devido à afetividade presente no conhecimento da própria cultura do(a) educando(a).

Já para o professor Osvaldo dos Santos Barros, a ponte entre o conhecimento primeiro e o científico é feita apenas daquilo que a ciência elege como elemento de transição do tradicional para o científico: "Essa ponte, ela não é feita de uma maneira geral, ela é específica diante daquilo que a ciência elege como elemento de transição do tradicional para o científico. Não são todas as situações, são os elementos específicos que ele reconhece" (BARROS, 2019, entrevista).

Cabe ressaltar que, com a interlocução do conhecimento escolar com o do cotidiano, um sabernão pode se impor sobre o outro. Sobre o assunto, o professor Milton Rosa relata:

Porque o que nós vemos na história, por exemplo, é a imposição de um conhecimento sobre o outro. O conhecimento que é mais fraco, geralmente ele padece, né? $\mathrm{E}$ esse conhecimento, ele não tem uma voz para que se possa contrapor o outro, né?, que tá tentando impor um conhecimento mais... um outro tipo de conhecimento. Então, essa questão dialógica também é importante, ela tem que acontecer, principalmente, com alteridade, né? Com respeito a todas as diferenças. Mas eu entendo que para os dois, que para as duas culturas, é interessante porque o Ubiratan D'Ambrosio comenta o seguinte: quando duas culturas se encontram você tem, por exemplo, culturas A e B, né? Você tem a cultura A que pode se prevalecer sobre a B, a cultura B que vai prevalecer sobre a $\mathrm{A}$ ou as duas culturas interagindo de uma maneira constante e frequente. (ROSA, 2018, entrevista) 
O depoente ressalta a importância de um conhecimento não se impor a outro, para o saber mais fraco não padecer. Com efeito, o discurso dos(as) depoentes revela como elemento emergente o diálogo entre os conhecimentos escolar e do cotidiano e a ponte entre esses conhecimentos. Esse diálogo é importante para que um conhecimento não se imponha sobre o outro, e a ponte entre esses saberes não pode ser entendida como uma evolução de um conceito para outro, pois isso indicaria que o conceito ligado ao cotidiano do(a) educando(a) seria menos legítimo que o conhecimento acadêmico.

Freire (1967) expõe que o diálogo nasce de uma relação horizontal de A com B e nutre-se da confiança, da simpatia, do amor, da humildade, da esperança e da fé; e afirma que só assim há comunicação. Com o diálogo, um cresce com o outro, em uma troca de experiências contínuas, pois o diálogo se faz em uma relação em conjunto de "A" com "B", e não impostas de "A" para "B" ou de "A" sobre "B".

\section{CONSIDERAÇÕES}

Neste trabalho, buscamos analisar se é possível estabelecer uma ponte entre o conhecimento escolar e o conhecimento do cotidiano na formação inicial de professores e professoras que ensinam matemática.

Com base no relato dos(as) depoentes, identificamos que, ao considerar que o conhecimento do cotidiano dialoga com o conhecimento escolar, é preciso também ter em conta a interferência do contexto e o interesse das partes em promovê-lo. $\mathrm{Na}$ formação inicial de professores(as), é o(a) educador(a) formador(a) o(a) responsável por fazer a ponte entre o conhecimento acadêmico e o conhecimento do cotidiano dos(as) graduandos(as), sem que haja imposição de um conhecimento sobre o outro. $\mathrm{O}(\mathrm{a})$ professor(a) formador(a) precisa proporcionar aos professores e às professoras em formação o melhor processo de ensino e aprendizagem do qual eles possam dispor. E estamos convictos de que isso se dará ao levar em consideração o conhecimento que eles(elas) trazem de suas experiências primeiras, decorrentes do seu entorno social e cultural.

Além disso, esse processo de formação inicial necessita ser pautado não só no respeito, mas na deferência ao conhecimento prévio dos educandos e das educandas, partindo do que eles(elas) sabem, para que possam aprender cada vez mais e melhor, sempre motivando as aprendizagens e pondo-se no lugar do outro.

Essa devolutiva só será possível a partir do diálogo, pois é através do processo dialógico entre professor(a) formador(a) e professor(a) em formação que são compartilhados conhecimentos matemáticos que advêm de diversos contextos sociais e culturais, que devem ser reconhecidos, respeitados e valorizados para que possamos ter uma educação mais justa e igualitária, uma formação sem cabrestos, livre de preconceitos e discriminações.

O conhecimento do cotidiano também se caracteriza como um conhecimento científico, porém ele não é acadêmico. E esse conhecimento do cotidiano precisa dialogar com o conhecimento escolar. No entanto, sua interlocução sofre a interferência de alguns fatores, tais como o contexto em que vai ocorrer esse diálogo e o interesse das partes em promovê-lo.

$\mathrm{Na}$ formação inicial de professores(as) que ensinam matemática, é o(a) professor(a) formador(a) o(a) responsável por instigar essa interlocução do conhecimento do cotidiano do educando e da educanda com o conhecimento escolar, através do diálogo, sem que haja imposição de um saber sobre o outro. $\mathrm{O}$ (a) docente formador(a) precisa pautar suas aulas pelo conhecimento prévio do educando e da educanda e, através do diálogo, construir uma ponte 
entre o conhecimento do cotidiano deles(delas) e o conhecimento escolar. No entanto, essa ponte necessita de uma linguagem adequada por parte do(a) professor(a) formador(a), para que ela não seja entendida como uma evolução de um conceito para outro, pois isso indicaria ser menos legítimo o conhecimento ligado ao cotidiano dos educandos e das educandas do que o conhecimento acadêmico.

\section{REFERÊNCIAS}

ALVES-MAZZOTTTI, Alda Judith; GEWANDSZNAJDER, Fernando. O método nas ciências naturais e sociais: pesquisa quantitativa e qualitativa. São Paulo: Pioneira, 1999.

COSTA, Rodrigo Tadeu Pereira. Formação inicial de professores e professoras que ensinam matemática: olhares e movimentos a partir da Etnomatemática. 2021. 288 f. Tese (Doutorado em Educação) Universidade de São Paulo, São Paulo, 2021.

D’AMBROSIO, Ubiratan. Etnomatemática e educação. In: KNIJNIK, Gelsa et al. (org.). Etnomatemática: currículo e formação de professores. Santa Cruz do Sul: EDUNISC, 2004. p. 3952.

D’AMBROSIO, Ubiratan. Etnomatemática, justiça social e sustentabilidade. Estudos Avançados, São Paulo, v. 32, n. 94, set./dez. 2018.

D’AMBROSIO, Ubiratan. Notas sobre a formação de professores e professoras numa perspectiva da Etnomatemática. In: Congresso Brasileiro de Etnomatemática, 1., 2000, São Paulo. Anais... São Paulo: USP, 2000.

D’AMBROSIO, Ubiratan. Sociedade, cultura, matemática e seu ensino. Educação e Pesquisa, São Paulo, v. 31, n. 1, p. 99-120, jan./abr. 2005.

DOMITE, Maria do Carmo Santos. Etnomatemática e formação de professores: no meio do caminho (da sala de aula) há impasses. In: Conferência Interamericana de Educación Matemática - CIAEM, 13., 2011, Recife. Anais... Recife, 2011.

FREIRE, Paulo. Educaşão como prática da liberdade. Rio de Janeiro: Paz e Terra, 1967.

FREIRE, Paulo. Pedagogia do oprimido. 17. ed. Rio de Janeiro: Paz e Terra, 1987.

FREIRE, Paulo. Pedagogia da esperança: um reencontro com a pedagogia do oprimido. Rio de Janeiro: Paz e Terra, 1992.

FREIRE, Paulo. Pedagogia da autonomia: saberes necessários à prática educativa. 25. ed. São Paulo: Paz e Terra, 1996.

FREIRE, Paulo; D’AMBROSIO, Ubiratan; DOMITE, Maria do Carmo Santos. Paulo Freire entrevistado por Ubiratan D'Ambrosio. In: International Congress on Mathematical Education, 8., 1996, Sevilha, Espanha. São Paulo: FEUSP, 1996. Vídeo. 
Informações do(a) autor(a)

Rodrigo Tadeu Pereira da Costa

SME/Londrina

E-mail: costa tadeu rodrigo@hotmail.com

ORCID: https://orcid.org/0000-0003-2582-3399

Link Lattes: http://lattes.cnpq.br/6684552537288553

Cristiane Coppe de Oliveira

UFU-GEPEm/FEUSP

E-mail: coppedeoliveira@gmail.com

ORCID: https://orcid.org/0000-0002-0378-810X

Link Lattes: http://lattes.cnpq.br/1337700960486255 